\title{
Vitamin D deficiency and anemia: a cross-sectional study
}

\author{
John J. Sim • Peter T. Lac In Lu A. Liu • \\ Samuel O. Meguerditchian • Victoria A. Kumar • \\ Dean A. Kujubu $\cdot$ Scott A. Rasgon
}

Received: 20 May 2009 / Accepted: 5 October 2009 / Published online: 20 October 2009

(C) The Author(s) 2009. This article is published with open access at Springerlink.com

\begin{abstract}
Vitamin D has been suggested to have an effect on erythropoiesis. We sought to evaluate the prevalence of anemia in a population of individuals with vitamin D deficiency compared with those with normal levels in a population of a large integrated healthplan. A cross-sectional analysis in the period 1 January 2004 through 31 December 2006 of subjects with documented concurrent levels of 25hydroxyvitamin D and hemoglobin were evaluated. Vitamin $\mathrm{D}$ deficiency was defined as $<30 \mathrm{ng} / \mathrm{mL}$ and anemia was defined as a hemoglobin $<11 \mathrm{~g} / \mathrm{dL}$. A total of 554 subjects were included in the analysis. Anemia was present in $49 \%$ of 25-hydroxyvitamin D-deficient subjects compared with $36 \%$ with normal 25 -hydroxyvitamin D levels $(p<0.01)$. Odds ratio for anemia in subjects with 25 -hydroxyvitamin $\mathrm{D}$ deficiency using logistic regressions and controlling for age, gender, and chronic kidney disease was 1.9 (95\% CI 1.32.7). 25-hydroxyvitamin D-deficient subjects had a lower mean $\mathrm{Hb}(11.0$ vs. $11.7 ; p=0.12)$ and a higher prevalence of erythrocyte stimulating agent use $(47 \%$ vs. $24 \% ; p<0.05)$.
\end{abstract}

As the corresponding author, I attest to the fact that this manuscript has been seen and approved by all authors and that it is not under consideration for publication elsewhere in a similar form, in any language, except in abstract form.

J. J. Sim $(\bowtie) \cdot$ P. T. Lac · S. O. Meguerditchian • V. A. Kumar •

D. A. Kujubu $\cdot$ S. A. Rasgon

Division of Nephrology and Hypertension,

Kaiser Permanente Los Angeles Medical Center,

4700 Sunset Blvd., 2nd Floor Nephrology,

Los Angeles, CA 90027, USA

e-mail: John.j.sim@kp.org

I. L. A. Liu

Department of Research and Evaluation,

Kaiser Permanente Southern California,

100 S. Los Robles Av,

Pasadena, CA 91107, USA
This study demonstrates an association of vitamin D deficiency and a greater risk of anemia, lower mean hemoglobin, and higher usage of erythrocyte-stimulating agents. Future randomized studies are warranted to examine whether vitamin D directly affects erythropoiesis.

Keywords Anemia $\cdot$ Vitamin D

\section{Background}

New insights into the biologic functions of vitamin D have led to interest in the clinical consequences of vitamin D deficiency. In addition to its role in regulation of bone and mineral metabolism, vitamin $\mathrm{D}$ has been implicated in a wide array of biological actions including muscle strengthening [1,2], cellular proliferation and differentiation [3-6], immune system modulation $[2,3,5,7]$, inhibition of renin synthesis [8], and insulin production [9].

The role of vitamin $\mathrm{D}$ in erythropoiesis has also been suggested by several clinical observations. In the hemodialysis population, vitamin $\mathrm{D}$ repletion has been associated with dose reductions in erythrocyte-stimulating agents (ESA) and increased reticulocytosis [10, 11]. Vitamin D has been demonstrated in bone marrow to affect marrow function $[12,13]$. Moreover, levels of 1,25 hydroxyvitamin D (the active form of vitamin D) are several hundred-fold higher in bone marrow compared with plasma [14]. Despite these intriguing observations, there is overall paucity of clinical studies investigating whether adequacy of vitamin D affects blood hemoglobin $(\mathrm{Hb})$ levels.

We undertook this study to evaluate whether an association exists between 25-hydroxyvitamin D (D25) deficiency and anemia in a population of individuals with and without chronic kidney disease (CKD). Using the database of a large 
integrated healthplan, we sought to assess the prevalence and risk of anemia in a population of subjects with documented D25 deficiency compared with those with normal D25 levels.

\section{Methods}

\section{Study design}

Kaiser Permanente Southern California (KPSC) is an integrated healthplan comprising of 11 medical centers and dozens of satellite clinics. KPSC covers the region from Bakersfield to San Diego within a similar sun exposure environment. These data were collected as part of normal healthcare operations. All members have very similar access to care for healthcare services, including office visits, tests, and medications. Potentially eligible subjects were those aged $>17$ years old with a minimum of one D25 and one hemoglobin $(\mathrm{Hb})$ level between January 1, 2004 and December 31, 2006 were identified using internal lab codes. Quantitative determination of serum 25OHD was performed using the Nichols Advantage 25-OHD Assay (Nichols Institute Diagnostics, San Clemente, CA).

Anemia was defined as an $\mathrm{Hb}$ level $<11 \mathrm{~g} / \mathrm{dL}$ for both men and women. D25 deficiency was defined as a level $<30 \mathrm{ng} /$ $\mathrm{mL}$. All unique subjects with an $\mathrm{Hb}$ level drawn within 6 months of a D25 value were included in the analysis. This included individuals with and without kidney disease but not restricted to patients with kidney disease. If multiple $\mathrm{Hb}$ values were drawn within the 6-month time period, the $\mathrm{Hb}$ value closest in time to the $\mathrm{D} 25$ level was used. If multiple D25 levels were drawn, the first D25 value with a concurrent (within 6 months) hemoglobin value was selected for analysis.

Data regarding age, gender, creatinine, estimated glomerular filtration rate (eGFR), calcium, phosphorus, serum albumin, ESA use, iron saturation, and ferritin were collected when available. Kidney function was assessed by the abbreviated Modification of Diet in Renal Disease study equation, which calculates eGFR based on serum creatinine, age, sex, and black vs. non-black race $[15,16]$. Conditions associated with inflammation/malnutrition can affect levels of D25. Thus, patients with diabetes mellitus, systemic lupus erythematosus, ulcerative colitis, and crohn's disease were identified based on ICD-9 coding. Patients with iron deficiency anemia, folic acid deficiency, vitamin B12 deficiency, bacteremia and gastrointestinal bleed diagnosed within 6 months of the cross-sectional time frame were excluded from the study. Patients with a previous history of sickle cell anemia, thalassemia, malignancies, myelodysplastic syndromes, and hemolytic anemia were also excluded. The study protocol was approved by the institutional review board of Kaiser Permanente Southern California.

\section{Statistics}

Univariate and multivariate logistic regression analyses were used to calculate the odds ratio (OR) for anemia. Confounding factors including age, eGFR $<60 \mathrm{~mL} / \mathrm{min} /$ $1.73 \mathrm{~m}^{2}$, gender, black or non-black race, and ESA use were included in the analysis. Secondary analyses compared prevalence of anemia, absolute $\mathrm{Hb}$ levels, and prevalence of ESA use in subjects with D25 deficiency compared with those with normal D25 levels.

The chi-square and Fisher's exact tests were used to compare the categorical variables including gender, percentage of African Americans in the study cohort, iron saturation percentage, eGFR $<60 \mathrm{~mL} / \mathrm{min} / 1.73 \mathrm{~m} 2$, ESA use, percentage of hemoglobin $<11$.

Student's $t$ test was used to assess for continuous variables. Significance was evaluated using a two-sided $p$ value of less than 0.05 . A multivariable logistic regression examined the simultaneous influence of several variables on the risk for anemia.

All statistics were performed by using SAS version 9.13. (SAS Institute, Inc. Cary, North Carolina)

\section{Results}

Study subjects

A total of 554 subjects had concurrent $\mathrm{Hb}$ and D25 levels within a 6-month period documented in the study period. Of these subjects, $240(43 \%)$ were D25 deficient and 314 (57\%) had normal D25 levels. Patients with CKD with an eGFR $<60 \mathrm{~mL} / \mathrm{min} / 1.73 \mathrm{~m}^{2}$ accounted for $65 \%$ of the study population. Baseline characteristics and demographics are described in Table 1.

Baseline characteristics of subjects according to D25 level are described in Table 2. Among subjects with D25 deficiency, $81 \%$ had an eGFR $<60 \mathrm{~mL} / \mathrm{min} / 1.73 \mathrm{~m}^{2}$ vs $53 \%$ of subjects with D25 levels $\geq 30 \mathrm{ng} / \mathrm{ml}(p=<0.0001)$. Mean serum ferritin level was $364 \mathrm{vs.} 189 \mathrm{ng} / \mathrm{ml}(p<0.01)$ and mean total iron-binding capacity (TIBC) was 278 vs. $325 \mathrm{mcg} / \mathrm{dl}(p<0.01)$ for subjects with D25 levels $<30$ and $\geq 30 \mathrm{ng} / \mathrm{ml}$, respectively. Forty seven percent of D25deficient subjects were on ESA vs. $23 \%$ of subjects with normal D25 levels $(p<0.01)$.

\section{Primary analysis}

Results of logistic regression analyses with and without adjustment for covariates are described in Table 3. In subjects with D25 deficiency, the OR for anemia controlling for age, gender, ESA use, and eGFR $<60 \mathrm{~mL} / \mathrm{min} /$ 
Table 1 Subject population characteristics

\begin{tabular}{lll}
\hline & & Number of patients \\
\hline Mean age (years) & 65 & 554 \\
Female (\%) & 65 & 360 \\
Race & & \\
$\quad$ Black (\%) & 21 & 117 \\
CKD (\%; GFR $<60 \mathrm{~mL} / \mathrm{min} /$ & 65 & 361 \\
$\left.\quad 1.73 \mathrm{~m}^{2}\right)$ & & \\
Iron indices & $26 \%$ & 393 \\
Iron saturation & $289 \mathrm{ng} / \mathrm{mL}$ & 376 \\
Ferritin & $67 \mathrm{mcg} / \mathrm{dL}$ & 404 \\
Iron & $302 \mathrm{mcg} / \mathrm{dL}$ & 392 \\
TIBC & 34 & 187 \\
Percent on ESA & & \\
\hline
\end{tabular}

$N=554$

$1.73 \mathrm{~m}^{2}$ was 1.86 (95\% CI 1.29-2.68) compared with subjects without D25 deficiency. Other variables including age, gender, ESA use, and eGFR $<60 \mathrm{~mL} / \mathrm{min} / 1.73 \mathrm{~m}^{2}$ were not statistically significant in the multivariate regressions analyses (Table 3 ).

\section{Secondary analysis}

The prevalence of anemia in the D25-deficient group was $48 \%(n=117)$ compared with $36 \%(n=112)$ in normal D25 group (Table 2). Of the 554 subjects, 228 (41\%) had moderate vitamin D25 deficiency (D25 11-29 ng/ml) and $12(2 \%)$ had severe vitamin D deficiency $(\leq 10 \mathrm{ng} / \mathrm{ml})$ totaling to $240(43 \%)$. In subjects with moderate and severe D25 deficiency, 109 (48\%) and eight (67\%) were anemic, respectively.

In subjects not on ESA therapy, mean $\mathrm{Hb}$ levels were $11.2 \mathrm{~g} / \mathrm{dL}$ in the D25-deficient group compared with $11.8 \mathrm{~g} /$ $\mathrm{dL}$ in the normal D25 group $(p<0.01)$. In terms of ESA use, $47 \%$ of D25-deficient subjects were on ESA therapy versus $24 \%$ in the group with normal D25 levels $(p<0.01)$.

In individuals where albumin and diabetes mellitus data were available, there were significant differences in mean albumin and diabetes mellitus rates between D25-deficient and normal individuals (albumin 3.1 vs $3.4, p<0.01$; diabetes mellitus $65 \%$ vs $43 \%, p<0.01$ ). D25-deficient patients had lower rates with normal albumin levels ( $\geq 4 \mathrm{~g} / \mathrm{dL})$ than D25 normal patients $(50 \%$ vs $67 \%$; $<0.01)$. In anemia patients, albumin and D25 had a significant correlation (Pearson's
Table 2 Subject characteristics by vitamin $\mathrm{D}$ status
$N=554$

${ }^{\mathrm{a}}$ Chi-square test

${ }^{\mathrm{b}}$ Student's $t$ test

${ }^{\mathrm{c}}$ Fisher's exact test

${ }^{\mathrm{d}}$ Secondary outcome data

\begin{tabular}{|c|c|c|c|}
\hline & $\mathrm{D} 25<30$ & $\mathrm{D} 25 \geq 30$ & $p$ value \\
\hline Number of individuals & 240 & 314 & \\
\hline Mean D25 level & $20.9( \pm 5.8)$ & $47.2( \pm 14.8)$ & \\
\hline Female $(\%)$ & 61.3 & 67.8 & 0.11 \\
\hline Mean Age (years) & 66.4 & 64.2 & 0.08 \\
\hline Blacks $(\%)$ & 21.3 & 21.0 & $0.68^{\mathrm{a}}$ \\
\hline Ferritin $(\mathrm{ng} / \mathrm{mL})$ & 364 & 189 & 0.01 \\
\hline Iron saturation $(\%)$ & 28 & 24.8 & 0.06 \\
\hline TIBC (mcg/dL) & 278 & 325 & $<0.01$ \\
\hline $\mathrm{eGFR}<60 \mathrm{~mL} / \mathrm{min} / 1.73 \mathrm{~m}^{2}(\%)$ & 80.8 & 53.2 & $<0.01$ \\
\hline Mean albumin $( \pm \mathrm{SD})$ & $\begin{array}{l}3.1( \pm 0.8) \\
N=188\end{array}$ & $\begin{array}{l}3.4( \pm 0.7) \\
N=187\end{array}$ & $<0.01^{\mathrm{b}}$ \\
\hline Diabetes mellitus (\%) & $\begin{array}{c}65.4 \\
N=157\end{array}$ & $\begin{array}{c}43.0 \\
N=135\end{array}$ & $<0.01$ \\
\hline Sytemic lupus erythematosus (\%) & $\begin{array}{r}3.8 \\
N=9\end{array}$ & $\begin{array}{c}1.3 \\
N=4\end{array}$ & $0.06^{\mathrm{c}}$ \\
\hline Crohn's disease $(\%)$ & $\begin{array}{c}2.1 \\
N=5\end{array}$ & $\begin{array}{c}0.6 \\
N=2\end{array}$ & $0.25^{\mathrm{c}}$ \\
\hline Ulcerative colitis $(\%)$ & $\begin{array}{c}1.3 \\
N=3\end{array}$ & $\begin{array}{c}0.3 \\
N=1\end{array}$ & $0.32^{\mathrm{c}}$ \\
\hline ESA use $(\%)^{d}$ & 47.1 & 23.6 & $<0.01$ \\
\hline $\mathrm{Hb}<11(\%)^{\mathrm{d}}$ & 48.8 & 35.7 & $<0.01$ \\
\hline \multicolumn{4}{|l|}{ Mean $\mathrm{Hb}$} \\
\hline Total & 11.0 & 11.7 & 0.12 \\
\hline Pt on ESA & $\begin{array}{c}10.9 \\
N=113\end{array}$ & $\begin{array}{c}11.3 \\
N=74\end{array}$ & $<0.01$ \\
\hline Pt not on $\mathrm{ESA}^{\mathrm{d}}$ & $\begin{array}{c}11.2 \\
N=127\end{array}$ & $\begin{array}{c}11.8 \\
N=240\end{array}$ & $<0.01$ \\
\hline
\end{tabular}


Table 3 Odds ratio for anemia using logistic regression analysis

\footnotetext{
${ }^{a}$ Each dependent variable is simultaneously adjusted for the other four covariables in the column
}

\begin{tabular}{lll}
\hline Dependent variable & OR $(95 \% \mathrm{CI})$ & OR with adjustments for covariables ${ }^{\mathrm{a}}(95 \% \mathrm{CI})$ \\
\hline Vit D $<30$ vs $\geq 30$ & $1.72(1.22-2.42)$ & $1.86(1.29-2.69)$ \\
Gender (male vs female) & $0.79(0.55-1.13)$ & $0.76(0.53-1.09)$ \\
Age $(<60$ vs $>60)$ & $0.99(0.63-1.57)$ & $0.93(0.58-1.50)$ \\
ESA use (yes vs no) & $1.17(0.82-1.67)$ & $1.17(0.79-1.76)$ \\
eGFR $(<60$ vs $\geq 60)$ & $1.08(0.71-1.63)$ & $1.06(0.70-1.63)$ \\
\hline
\end{tabular}

correlation coefficients $=0.21 ; p$ value $<0.01)$. Such a correlation did not exist for our non-anemia patients (Pearson's correlation coefficients $=0.12 ; p$ value $=0.09$ ). Rates of systemic lupus erythematosus, ulcerative colitis, and Crohn's disease were not significantly different between out D25-deficient and D25 normal individuals.

\section{Discussion}

This study demonstrates a greater prevalence and risk of anemia in individuals with D25 deficiency compared with those with normal D25 levels. The percentage of subjects with anemia and subjects on ESA therapy were higher in the D25 deficiency group compared with those with normal D25 levels. In addition, D25-deficient subjects also had a lower mean $\mathrm{Hb}$ level compared with those with normal D25 levels. A multivariate logistic regression analysis controlling for gender, age, renal insufficiency, and ESA use revealed an OR of 1.9 for anemia in subjects with D25 deficiency versus those with normal D25.

Subjects with D25 deficiency had higher serum iron saturations, ferritins, and lower TIBC levels compared with those with normal D25 levels. Thus, iron deficiency based on laboratory studies could not account for the higher proportion of anemia in subjects with low D25 levels. Although iron adequacy may not be a factor of anemia, the higher levels of ferritin and lower serum albumin does suggest that malnutrition and inflammation may have been more prevalent in D25-deficient individuals which introduces a confounder for the association evaluated in this study.

While our study found a correlation between D25 deficiency and anemia, a causal relationship cannot be established. There may have been additional confounding factors that played a role in reducing both erythropoiesis and D25 stores. For example, patients with anemia may have more illnesses and debility preventing them from adequate sun exposure. Concurrent D25 and Hb levels were drawn within 6 months of each other in this study, but D25 levels could have changed within 6 months of time and might not reflect true concurrent levels. The etiology of anemia was not evident for each individual, but common obvious causes such as iron, B12, and folate deficiency were excluded along with individuals with documented secondary causes of anemia such as blood and marrow disorders and anemia due to bleeding. Another possible confounder is selection bias inherent in the observational nature of the study.

Individuals who had their vitamin D levels drawn may have been disproportionately represented by patients that were seen by a certain specialty department and thus, not reflect the general patient population. The high prevalence of anemia itself reflects this bias. Anemia in of itself may have predisposed patients to D25 deficiency as anemic patients due to fatigue may have been less likely to go outside and obtain adequate sun exposure. Lastly, we did not separate anemia by gender as females generally have lower Hb levels than males. However, anemia was defined for this study as a level $<11 \mathrm{~g} / \mathrm{dL}$ which would be considered clinically significant for both genders.

A high percentage of patients with CKD (65\%) were included in this study, but a significant portion without CKD was also included. Chronic kidney disease can lower the total number of 1,25-hydroxyviatmin D levels because the kidney is the largest source for 1-alpha-hydroxylase in the body. The 1-alpha-hydroxylase converts D25 into active 1,25-hydroxyvitamin $\mathrm{D}$ which ultimately regulates bone and mineral health. The total systemic stores and levels of D25 however are and should not be directly affected by depressed kidney function.

In the D25-deficient population, 20\% had normal renal function (Table 2). This is consistent with observational data on the non-CKD population where D25 deficiency is not uncommon and even highly prevalent in certain subsets of the general population. For instance, the elderly, postmenopausal women, and individuals in colder climates have D25 deficiency rates exceeding $50 \%$ of the population [17-19]. Observations on the general populations have demonstrated prevalence rates around 15-25\% [17, 20]. Individuals with propensity for decreased skin synthesis of D25 or decreased gut absorption are at risk of D25 deficiency [4, 21].

Comorbidities such as inflammatory bowel disease and other conditions associated with malnutrition can affect gut absorption of D25. Thus, patients with diabetes mellitus, systemic lupus erythematosus, ulcerative colitis, and Crohn's disease were identified within D25 levels. Albumin 
was evaluated as a surrogate for nutritional status, and the significant difference present between the D25 normal and D25-deficient group further suggests the confounding of malnutrition in our study. Overall presence of systemic lupus erythematosus, ulcerative colitis, and Crohn's disease were rare in our study population and between D25deficient and D25 normal individuals.

This study evaluated clinically significant anemia based on D25 levels in patients with and without CKD. Previous studies have examined vitamin D deficiency and ESA usage in patients with end-stage renal disease (ESRD). Saab et al. [11] observed a reduction of epoetin alfa doses after treatment of D25 deficiency with ergocalciferol in hemodialysis-dependent patients, but anemia was not a primary outcome of the study [22]. Aucella et al. [23] demonstrated that administration of 1,25-hydroxyvitamin D increased burst-forming unit erythroid proliferation in patients with ESRD that was synergistic with epoetin alfa. Our study is one of the first to investigate the association of D25 and anemia that included subjects without CKD and/or not on ESA.

Vitamin D appears to be associated with anemia; though the mechanism is unknown. One possibility is that vitamin D modulates the level of systemic cytokine production thus reducing the inflammatory milieu that leads to anemia of chronic disease. Both in vivo and in vitro studies have demonstrated that calcitriol (1,25 hydroxyvitamin D) reduces cytokine production [14]. Interestingly, in our study, we found that patients with normal D25 levels had lower ferritin levels than D25-deficient patients. This may suggest a reduced state of chronic systemic inflammation in those with normal D25 or an ineffective erythropoiesis in D25-deficient patients.

Another possible mechanism is that vitamin D directly stimulates erythroid precursors. Vitamin D receptors have been discovered in numerous non-renal target tissues including the bone marrow $[12,13]$. Normalizing tissue D25 levels may provide an adequate substrate for local tissue production of 1,25 hydroxyvitamin $\mathrm{D}$ in hematopoietic tissues via extra-renal tissue activity of the 1-alphahydroxylase enzyme. Hematons (the buffy coat of bone marrow containing erythroid precursors, fibroblast, endothelial cells, lipid laden cells, and macrophages) have been demonstrated to contain significantly higher concentrations of D25 and 1,25-hydroxyvitamin D levels than bone marrow plasma [23]. High local concentrations of 1,25 hydroxyvitamin D in hematopoietic tissues may then directly activate erythroid precursor cells in a paracrine fashion.

Based on our findings of an association between D25 deficiency and anemia, further investigation needs to be conducted to evaluate whether there is a direct causal effect of D25 deficiency on anemia. If vitamin D does improve erythropoiesis then correction of a D25-deficient state may lead to improvement in anemia in patients with and without CKD.

Disclosures None.

Open Access This article is distributed under the terms of the Creative Commons Attribution Noncommercial License which permits any noncommercial use, distribution, and reproduction in any medium, provided the original author(s) and source are credited.

\section{References}

1. Zittermann A (2006) Vitamin D and disease prevention with special reference to cardiovascular disease. Prog Biophys Mol Biol 92:39-48

2. Bischoff-Ferrari HA, Giovannucci E, Willett WC, Dietrich T, Dawson-Hughes B (2006) Estimation of optimal serum concentrations of 25-hydroxyvitamin D for multiple health outcomes. Am J Clin Nutr 84:18-28

3. Holick MF, Garabedian M (2006) Primer on the metabolic bone diseases and disorders of mineral metabolism, 6th edn. American Society for Bone and Mineral Research, Washington, DC

4. Bouillon R, Sarandeses LA, Allewaert K, Zhao J, Mascarenas JL, Mourino A, Vrielynck S, de Clercq P, Vandewalle M (1993) Biologic activity of dihydroxylated 19-nor-(pre)vitamin D3. J Bone Miner Res 8:1009-1015

5. DeLuca HF (2004) Overview of general physiologic features and functions of vitamin D. Am J Clin Nutr 80:1689S-1696S

6. Dusso A, Brown A, Slatopolsky E (1994) Extrarenal production of calcitriol. Semin Nephrol 14:144-155

7. Penna G, Roncari A, Amuchastegui S, Daniel KC, Berti E, Colonna M, Adorini L (2005) Expression of the inhibitory receptor ILT3 on dendritic cells is dispensable for induction of CD4+Foxp3+ regulatory $\mathrm{T}$ cells by 1 , 25-dihydroxyvitamin $\mathrm{D} 3$. Blood 106:3490-3497

8. Li YC (2003) Vitamin D regulation of the renin-angiotensin system. J Cell Biochem 88:327-331

9. Chiu KC, Chu A, Go VL, Saad MF (2004) Hypovitaminosis D is associated with insulin resistance and beta cell dysfunction. Am J Clin Nutr 79:820-825

10. Albitar S, Genin R, Fen-Chong M, Serveaux MO, Schohn D, Chuet C (1997) High-dose alfacalcidol improves anaemia in patients on haemodialysis. Nephrol Dial Transplant 12:514518

11. Saab G, Young DO, Gincherman Y, Giles K, Norwood K, Coyne DW (2007) Prevalence of vitamin D deficiency and the safety and effectiveness of monthly ergocalciferol in hemodialysis patients. Nephron Clin Pract 105:c132-c138

12. Reichel H, Koeffler HP, Norman AW (1989) The role of the vitamin D endocrine system in health and disease. N Engl J Med 320:980-991

13. Norman AW (2006) Minireview: vitamin D receptor: new assignments for an already busy receptor. Endocrinology 147:5542-5548

14. Blazsek I, Farabos C, Quittet P, Labat ML, Bringuier AF, Triana BK, Machover D, Reynes M, Misset JL (1996) Bone marrow stromal cell defects and 1 alpha, 25-dihydroxyvitamin D3 deficiency underlying human myeloid leukemias. Cancer Detect Prev 20:31-42 
15. Alon DB, Chaimovitz C, Dvilansky A, Lugassy G, Douvdevani A, Shany S, Nathan I (2002) Novel role of 1, 25(OH)(2)D(3) in induction of erythroid progenitor cell proliferation. Exp Hematol 30:403-409

16. Levey AS, Bosch JP, Lewis JB, Greene T, Rogers N, Roth D (1999) A more accurate method to estimate glomerular filtration rate from serum creatinine: a new prediction equation. Modification of Diet in Renal Disease Study Group. Ann Intern Med 130:461-470

17. Gordon CM, DePeter KC, Feldman HA, Grace E, Emans SJ (2004) Prevalence of vitamin D deficiency among healthy adolescents. Arch Pediatr Adolesc Med 158:531-537

18. Holick MF, Siris ES, Binkley N, Beard MK, Khan A, Katzer JT, Petruschke RA, Chen E, de Papp AE (2005) Prevalence of Vitamin D inadequacy among postmenopausal North American women receiving osteoporosis therapy. J Clin Endocrinol Metab 90:3215-3224
19. McKenna MJ (1992) Differences in vitamin D status between countries in young adults and the elderly. Am J Med 93:6977

20. Chapuy MC, Preziosi P, Maamer M, Arnaud S, Galan P, Hercberg S, Meunier PJ (1997) Prevalence of vitamin D insufficiency in an adult normal population. Osteoporos Int 7:439-443

21. Holick MF (2006) High prevalence of vitamin D inadequacy and implications for health. Mayo Clin Proc 81:353-373

22. Panichi V, De Pietro S, Andreini B, Bianchi AM, Migliori M, Taccola D, Giovannini L, Tetta C, Palla R (1998) Calcitriol modulates in vivo and in vitro cytokine production: a role for intracellular calcium. Kidney Int 54:1463-1469

23. Aucella F, Scalzulli RP, Gatta G, Vigilante M, Carella AM, Stallone C (2003) Calcitriol increases burst-forming unit-erythroid proliferation in chronic renal failure, a synergistic effect with $\mathrm{r}$ HuEpo. Nephron Clin Pract 95:c121-c127 